\title{
Relación entre el coste de los servicios y la planta local
}

\section{Relationship between the cost of services and the territorial área}

\author{
Alejandro de Diego Gómez \\ Ayuntamiento de Avión (Ourense) \\ fusion.ayuntamientos@gmail.com
}

\section{RESUMEN}

En este informe se trata de analizar el comportamiento de los principales agentes que forman el sector público local y el coste efectivo de los servicios prestados por ellos según la publicación hecha por el Ministerio de Hacienda y Función Pública, llegando a la conclusión de la necesidad urgente de adelgazar y modernizar nuestra Administración Local para conseguir reducir el peso de los gastos generales, así como de modificar la planta municipal, proponiendo la fusión de los pequeños Ayuntamientos de forma que tengan la capacidad suficiente para responder a los retos y necesidades que les exige la población del Siglo XXI sin perder con ello su identidad.

\section{PALABRAS CLAVE}

Coste de los servicios, fusión de ayuntamientos, ámbito territorial.

\begin{abstract}
This report analyses the behavior of the main agents that form the local public sector and the actual cost of services which they provide according to the publication by the Ministry of Finance and Public Administration. The report concludes the urgent need to reduce and modernize our local Administration in order to decrease in overhead expenses, as well as modify the territorial area by proposing the merger of smaller municipalities in such a way to have sufficient capacity to respond to the challenges and needs that 21st Century world population demands without causing them to lose their identity.
\end{abstract}

\section{KEYSWORDS}

Cost of services, merger of municipalities, territorial scope.

\section{SUMARIO}

1. INTRODUCCIÓN. 2. ESTUDIO ECONÓMICO. 2.1. METODOLOGÍA. 2.2. GASTOS. 2.2.1. Clasificación por capítulos de gastos. 2.2.2. Clasificación por áreas de gastos. 2.3. INGRESOS. 2.3.1. Impuestos. 2.3.2. Transferencias corrientes. 2.3.3. Tasas, precios públicos y otros ingresos. 2.3.4. Transferencias de capital. 2.4. ESTABILIDAD PRESUPUESTARIA. 3. LOS AYUNTAMIENTOS POR TRAMOS DE POBLACIÓN. 3.1. AYUNTAMIENTOS DE MENOS DE 20.000 HABITANTES. 3.2. AYUNTAMIENTOS DE MENOS DE 5.000 HABITANTES. 3.3. AYUNTAMIENTOS DE MENOS DE 1.000 HABITANTES. 3.4. AYUNTAMIENTOS DE ENTRE 5.000 Y 7.000 HABITANTES 4. LOS GOBIERNOS PROVINCIALES. 4.1. DIPUTACIONES PROVINCIALES DE RÉGIMEN COMÚN. 4.2. LAS DIPUTACIONES PROVINCIALES Y LOS AYUNTAMIENTOS DE MENOS DE 20.000 HABITANTES. 4.3. LAS COMUNIDADES UNIPROVINCIALES. 5. OTRAS FIGURAS ASOCIATIVAS MUNICIPALES. 5.1. MANCOMUNIDADES. 5.2. COMARCAS. 5.3. ÁREAS METROPOLITANAS. 6. ENTIDADES DE ÁMBITO TERRITORIAL INFERIOR AL MUNICIPIO 7. CONCLUSIONES. 8. PROPUESTAS. PROPUESTA 1: La fusión de Ayuntamientos. PROPUESTA 2: Creación de una oficina autonómica de fusiones. PROPUESTA 3: Modificación de las Diputaciones Provinciales. PROPUESTA 4: Reforma de la financiación local. 9. REFLEXIÓN FINAL. BIBLIOGRAFÍA. 


\section{INTRODUCCIÓN}

El coste efectivo de los servicios es un concepto introducido por la Ley 27/2013, de 27 de diciembre, de Racionalización y Sostenibilidad de la Administración Local (LRSAL), como una medida de transparencia, considerada como un paso fundamental en la mejora de la información disponible, eliminando asimetrías, para la toma de decisiones de los ciudadanos y de la Administración, debiendo contribuir de forma permanente al cumplimiento del principio de eficiencia, de conformidad con lo dispuesto en el artículo 7 de la Ley Orgánica 2/2012, de 27 de abril, de Estabilidad Presupuestaria y Sostenibilidad Financiera (LOEPSF).

No existe una definición del coste efectivo de los servicios ni en la LRSAL ni en la Orden HAP/2075/2014, de 6 de noviembre, por la que se establecen los criterios de cálculo del coste efectivo de los servicios prestados por las entidades locales, haciendo referencia únicamente esta última a la Orden EHA/3565/2008, de 3 de diciembre, por la que se aprueba la estructura de los presupuestos de las entidades locales, y que supone presentar una mayor desagregación de la clasificación por programas que permitirá identificar con mayor precisión ese coste efectivo.

El artículo 116ter de la LRSAL establece que todas las entidades locales calcularán antes del 1 de noviembre de cada año el coste efectivo de los servicios que prestan, partiendo de los datos contenidos en la liquidación del presupuesto general y, en su caso, de las cuentas anuales aprobadas de las entidades vinculadas o dependientes, correspondiente al ejercicio inmediato anterior, debiendo comunicarlo al Ministerio de Hacienda y Función Pública para su publicación. Por su parte el artículo 3 de la Orden HAP/2075/2014, de 6 de noviembre, por la que se establecen los criterios de cálculo del coste efectivo de los servicios dispone que este será el resultado, para cada uno de ellos, de la aplicación de los criterios contenidos en la misma, y vendrá determinado por la agregación de dos componentes: costes directos, exclusivamente asociados a cada servicio, y costes indirectos determinados con arreglo a los criterios de imputación establecidos en dicha Orden.

\section{ESTUDIO ECONÓMICO}

Cualquier estudio económico es poco amable al convertirse en una sucesión de cifras y datos, pero es absolutamente necesario para comprender las conclusiones finales de este trabajo.

\subsection{Metodología}

Para la realización de este trabajo se han tenido en cuenta las liquidaciones de los presupuestos de Ayuntamientos con población inferior a 20.000 habitantes, por ser estos a los que les es de aplicación principal las medidas que prevé la LRSAL. Para ello se han utilizado los datos publicados en la Oficina Virtual para la Coordinación Financiera con las Entidades Locales del Ministerio de Hacienda y Función Pública correspondientes a los ejercicios de 2001 a 2015, ambos inclusive, exceptuando las Comunidades Forales de Navarra y el País Vasco ya que debido a sus especificidades, por su régimen de financiación autonómica, no constan sus datos en la web del Ministerio de Hacienda y Función Pública, así como las Ciudades Autónomas de Ceuta y Melilla, ya que cualquier conclusión a la que se pudiera llegar sobre posibles medidas de fusiones, agrupaciones, etc., no les serían de aplicación, pudiendo, sin embargo, desvirtuar los resultados finales del estudio.

Para poder relacionar entre sí los datos económicos se han utilizado como denominador común los importes per cápita de ingresos y gastos, por ser ésta una variable uniforme en cualquier comparativa, habiéndose tomado los datos de habitantes de la web del Instituto Nacional de Estadística. Igualmente, se han calculado los valores medios de esas variables presupuestarias, tomando para ello los datos de esos 15 ejercicios liquidados en su conjunto, para garantizar cierta estabilidad de la información manejada.

Para entender mejor la realidad local se estudian en este apartado los gastos, los ingresos y una comparativa entre gastos e ingresos ordinarios como indicador de estabilidad presupuestaria.

\subsection{Gastos}

Es evidente que según como se mire se puede pensar que no hay Ayuntamientos con servicios más caros que en otros sino que lo hagan con niveles mayores de prestación, o se puede hacer el razonamiento totalmente a la inversa. Para intentar resolver esta cuestión debemos hacer una primera aproximación de los datos publicados de las liquidaciones de los presupuestos de las entidades locales. 


\subsubsection{Clasificación por capítulos de gastos}

Para tener una correcta visión del comportamiento de los Ayuntamientos es interesante detenerse en algunos de los capítulos en que se ordenan los gastos públicos. Así el primer dato que podemos comparar es el total de recursos per cápita que destinaron de media durante el período estudiado los Ayuntamientos de menos de 20.000 habitantes, siendo este el de 965 euros.

Si nos detenemos en los capítulos según su repercusión sobre el total de gastos soportados, los tres más importantes, que suponen el $88 \%$ del total, fueron el de gastos de personal, comprensivo de todo tipo de retribuciones e indemnizaciones por razón del trabajo así como de las cotizaciones obligatorias, que se llevó el 32,33 \% del total; el de gastos corrientes en bienes y servicios, que recoge los gastos necesarios para el ejercicio de las actividades que no originen aumento de capital o de patrimonio público, así como los gastos en bienes de carácter inmaterial que puedan tener carácter reiterativo, no sean susceptibles de amortización y no estén directamente relacionados con la realización de las inversiones, que supuso el 30,57 $\%$ de la factura; y el de inversiones reales, comprensivo de los gastos destinados a la creación o adquisición de bienes de capital así como los destinados a la adquisición de bienes de naturaleza inventariable necesarios para el funcionamiento operativo de los servicios y aquellos otros de naturaleza inmaterial que tengan carácter amortizable, suponiendo el $25,39 \%$ del total.

GRÁFICO 1: GASTOS SEGÚN LOS PRINCIPALES CAPÍTULOS

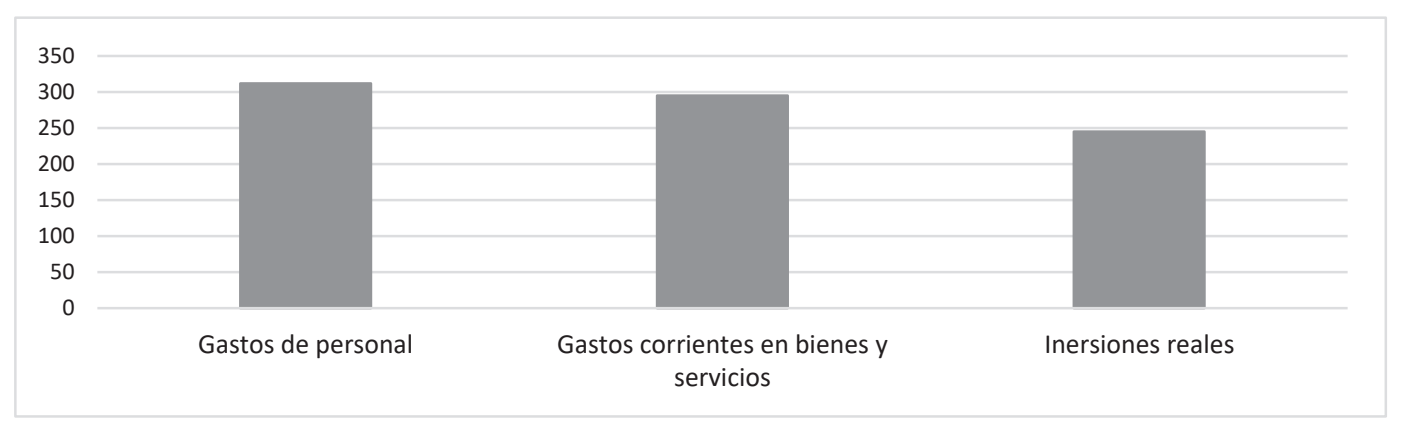

Fuente: elaboración propia

\subsubsection{Clasificación por áreas de gastos}

Si a mayores nos detenemos en las 4 áreas más importantes de Gastos de los Ayuntamientos objeto de este estudio, esto nos arroja los siguientes resultados:

\subsubsection{Servicios públicos básicos}

Esta área comprende todos aquellos originados por los servicios que, con carácter obligatorio, deben prestar los municipios con arreglo al artículo 26.1 de la LBRL. Y es la que contiene la partida más abultada, suponiendo el $41 \%$ del total del coste de los servicios públicos prestados por estos Ayuntamientos, con una media de 397 euros por habitante.

\subsubsection{Actuaciones de carácter general}

Es la segunda área en importe, e incluye los gastos relativos a actividades que consistan en el ejercicio de funciones de gobierno o de apoyo administrativo y de soporte lógico y técnico a toda la organización, recogiendo los gastos generales de la entidad que no puedan ser imputados ni aplicados directamente a otra área. El importe de gasto de esta área supone el $21,5 \%$ del total, con una media de 207 euros por habitante.

\subsubsection{Servicios de protección social}

Engloba aquellos gastos que constituyen el régimen de previsión, atenciones de carácter benéfico-asistencial, medidas de fomento del empleo, atenciones a grupos con necesidades especiales, como jóvenes, 
mayores, minusválidos físicos y tercera edad; y, en general, prestación de servicios sociales y promoción social, con cargo a los cuales se imputarán los gastos llevados a cabo para desarrollar la asistencia social primaria: la promoción de la igualdad de género, promoción y reinserción social de marginados, así como para la gestión de los servicios sociales, prestación de servicios a personas dependientes y de asistencia social, residencias de ancianos y otros de naturaleza análoga, la evaluación e información de situaciones de necesidad social y la atención inmediata a personas en situación o riesgo de exclusión social.

En contra de lo que pudiera pensarse a priori, esta área no ocupa un lugar preferente entre las áreas de gasto municipales, suponiendo el $11 \%$ del total, con una media per cápita de 104 euros por habitante, tres veces menos que los gastos de personal y la mitad que los gastos generales.

\subsubsection{Deuda pública}

Comprende los gastos de intereses y amortización de la deuda y demás operaciones financieras de naturaleza análoga, con exclusión de los gastos que ocasione la formalización de las mismas. El importe medio que el conjunto de estos Ayuntamientos estudiados destinaron a gastos relacionados con su deuda fue de 54 euros por habitante, suponiendo el $5,5 \%$ del total.

\section{GRÁFICO 2: GASTOS SEGÚN LAS PRINCIPALES ÁREAS}

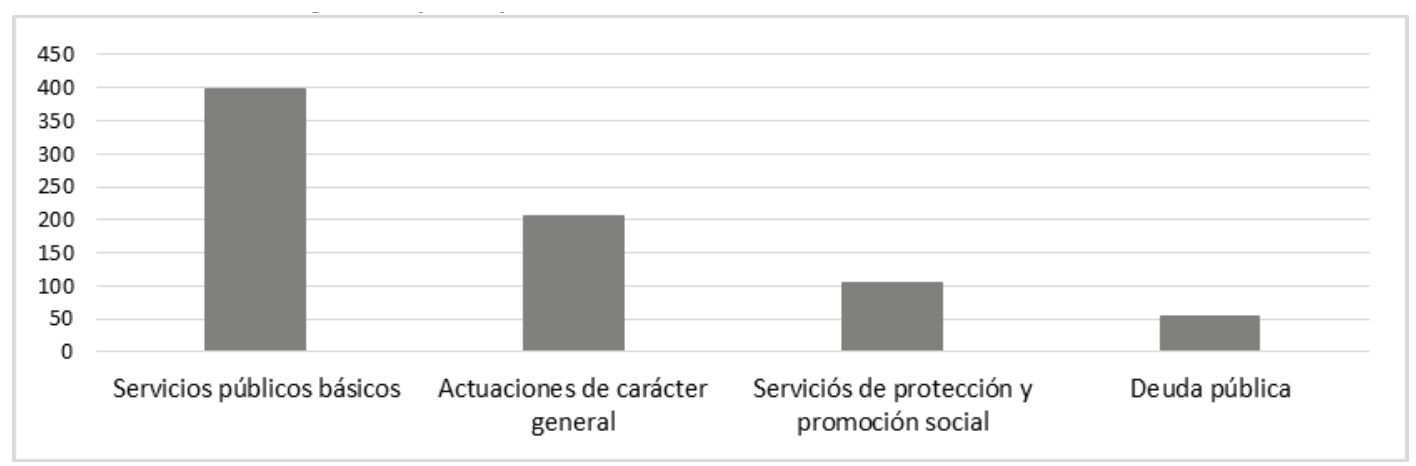

Fuente: elaboración propia

\subsection{Ingresos}

Son 5 los Capítulos más importantes de ingresos, que suponen el 89,7 \% del total, aunque a efectos de este estudio los agruparé en 4 , unificando en uno el referido a impuestos.

\subsubsection{Impuestos}

El primer capítulo de ingresos en importancia es el de impuestos, y aunque suponen dos capítulos en la clasificación de ingresos: «impuestos directos», que comprenden todo tipo de recursos exigidos sin contraprestación cuyo hecho imponible esté constituido por negocios, actos o hechos de naturaleza jurídica o económica que pongan de manifiesto la capacidad contributiva del sujeto pasivo como consecuencia de la posesión de un patrimonio o la obtención de renta; e «impuestos indirectos», que incluyen todo tipo de recursos exigidos sin contraprestación cuyo hecho imponible esté constituido por negocios, actos o hechos de naturaleza jurídica o económica que pongan de manifiesto la capacidad contributiva del sujeto pasivo como consecuencia de la circulación de los bienes o el gasto de la renta, sin embargo se han agrupado como un solo concepto en este estudio, a pesar de ser más importantes para la hacienda municipal los primeros que los segundos. Así, el peso total de las figuras impositivas supone el 30,9\% del total de los ingresos municipales, correspondiendo el $27,44 \%$ a los impuestos directos y tan sólo el $3,45 \%$ a los indirectos.

\subsubsection{Transferencias corrientes}

Suponen el segundo recurso de los Ayuntamientos estudiados, muy cerca de los impuestos, lo que denota su dependencia de otras Administraciones territoriales y por tanto su falta de autonomía local, com- 
prendiendo los recursos recibidos sin contrapartida directa. Representan el $27,54 \%$ del total, una décima más que los impuestos directos.

El $97 \%$ de la procedencia de esas transferencias corrientes viene de la Administración Central y Administraciones territoriales, las más importantes de las cuales, suponiendo más de la mitad de todos los ingresos por este concepto (56 \%), provienen del Estado, el $33 \%$ de las Comunidades Autónomas y el $11 \%$ de las Diputaciones provinciales, Cabildos y Consejos insulares.

\subsubsection{Tasas, precios públicos y otros ingresos}

Son el tercer capítulo por volumen de recursos, e incluye, entre otros, los ingresos derivados de la utilización privativa o aprovechamiento especial del dominio público, de la prestación de servicios o de la realización de actividades en régimen de Derecho público que se refieran, afecten o beneficien de modo particular al obligado tributario cuando los servicios o actividades no sean de solicitud voluntaria y no se presten por el sector privado, o de hacerlo, sean de solicitud voluntaria por parte de los administrados, suponiendo el 17,28 $\%$ del total de ingresos.

\subsubsection{Transferencias de capital}

Es el último de los capítulos principales de ingresos, y comprende los recursos, condicionados o no, recibidos por los Ayuntamientos sin contrapartida directa por parte de los agentes que los reciben, y que se destinan a financiar operaciones de capital, suponiendo el $14 \%$ del total, más de 3 puntos por debajo de las tasas y precios públicos y casi la mitad de lo que suponen tanto los impuestos directos como las transferencia corrientes.

GRÁFICO 3: INGRESOS SEGÚN LOS PRINCIPALES CAPÍTULOS

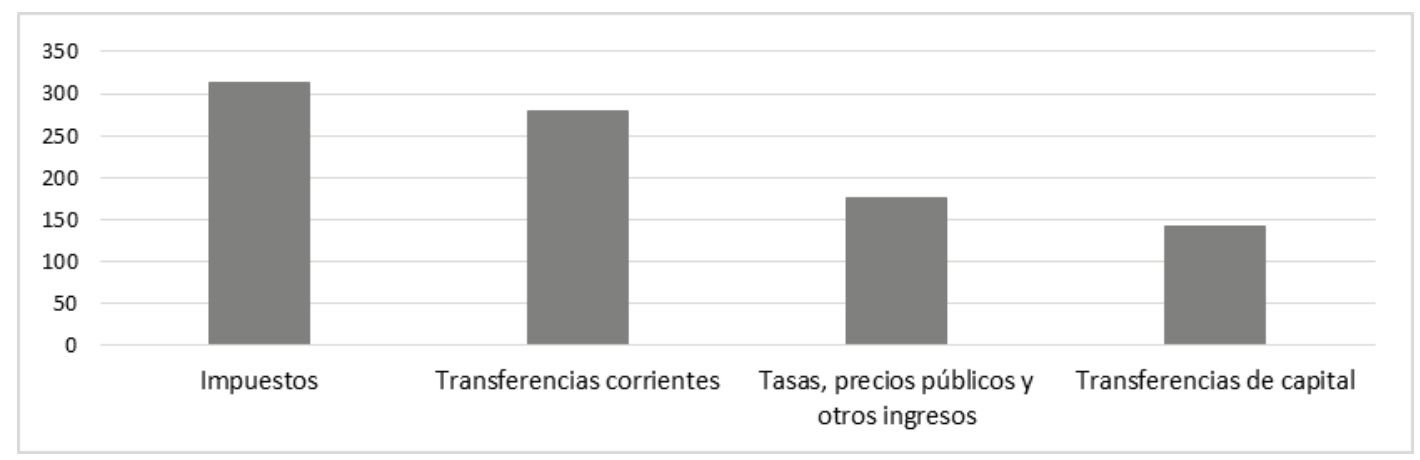

Fuente: elaboración propia

\subsection{Estabilidad presupuestaria}

Como colofón de este estudio económico voy a referirme brevemente a los datos de estabilidad presupuestaria de los Ayuntamientos estudiados. Así el artículo 3,2 de la LOEPSF establece que se entenderá por ésta en las Administraciones Públicas la situación de equilibrio o superávit estructural. La constatación de éste principio se realiza en base a los cálculos efectuados y ajustes practicados conforme al Manual de la Intervención General del Estado de cálculo del déficit en contabilidad nacional adaptado a las Corporaciones Locales, tal y como lo interpreta la Subdirección General de Relaciones Financieras con las Entidades Locales, sobre la base de los Capítulos 1 a 7 de los estados tanto de ingresos como de gastos presupuestarios, en términos de Contabilidad Nacional.

De los datos comparados se comprueba cómo la Administración Local española, referida a los Ayuntamientos estudiados de menos de 20.000 habitantes, es una Administración equilibrada o estable presupuestariamente, con recursos suficientes para hacer frente a sus gastos con un diferencial de 4 puntos durante el conjunto del período escogido. Aunque en los peores momentos de la crisis económica esto no fue así, ya que entre los años 2008 a 2011el diferencial, por el período, fue de $-1,03$ puntos, sobre todo por el comportamiento del ejercicio de 2008 donde el diferencial fue de $-3,39$ puntos, subiendo a $-0,60$ en $2009,-0,15$ en 2010 y a $-0,07$ en 2011, estando ya en 2015 en 11,16 puntos positivos. 
GRÁFICO 4: EVOLUCIÓN DE LOS INGRESOS Y GASTOS PARA EL CÁLCULO DE ESTABILIDAD PRESUPUESTARIA

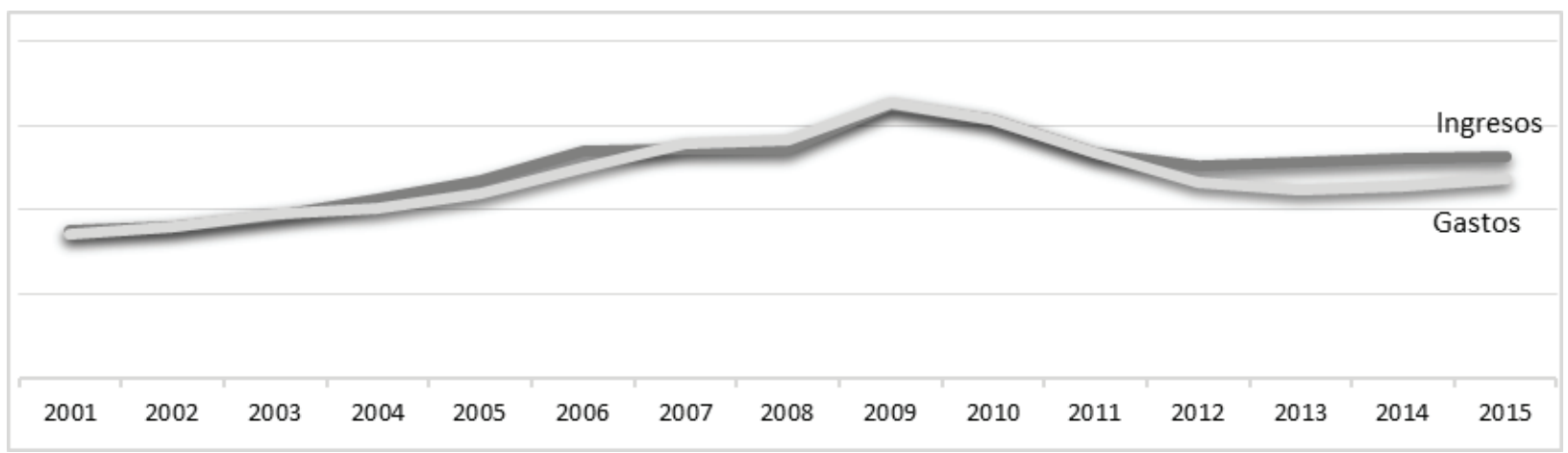

Fuente: elaboración propia

Pero si confrontamos entre si las operaciones corrientes de ingresos con las de gastos nos darán unos resultados totalmente distintos. Así, el diferencial total entre ingresos y gastos por los Ayuntamientos y período estudiado fue de $+18,6$ puntos, y en los años peores de la crisis estuvo en $+11,88$ puntos, siendo positivo en todos y cada uno de esos años. Si además en los gastos incluimos el Capítulo 9, de pasivos financieros, el diferencial total del período estaría en $+11,54$ puntos, es decir, casi tres veces más que tomando en consideración los capítulos de estabilidad presupuestaria, y si nos detenemos en esos años peores de la crisis el diferencial estuvo siempre en positivo, con un resultado global de $+6,8$ puntos.

Con todo ello se acredita que los Ayuntamientos españoles, especialmente los de menos de 20.000 habitantes, tienen recursos propios no sólo para hacer frente a sus gastos corrientes sino también a su deuda. Cosa distinta es cuando necesitan hacer inversiones, ya sea en equipamientos o en infraestructuras. Para ello necesitan la colaboración de otras Administraciones Públicas, y la experiencia nos indica que las Comunidades Autónomas, cuando tienen dificultades, piensan primero en sí mismas, aunque esto conlleve prácticamente el desatender sus compromisos con los municipios y aunque se trate de gasto destinado al progreso y desarrollo de los pueblos. Por lo que no sólo es necesaria, sino también urgente, una Ley de Financiación Local que no sólo aclare y regule los ingresos de los Ayuntamientos sino que también los blinde ante los vaivenes autonómicos.

\section{LOS AYUNTAMIENTOS POR TRAMOS DE POBLACIÓN}

En España, según el Registro de Entidades Locales del Ministerio de Hacienda y Función Pública, existen un total de 8.123 Ayuntamientos de los que tan sólo 96 cuentan con más de 75.000 habitantes, siendo, resumidamente, los considerados «de gran población» por la LBRL, es decir escasamente un 1,2\% del total aunque en ellos vive el $46 \%$ de la población según los datos del Instituto Nacional de Estadística, mientras que 4.955 Ayuntamientos tienen menos de 1.000 habitantes, lo que supone nada menos que el $61 \%$ y en los que, sin embargo, vive el $3 \%$ de la población, cifra ésta que disminuye constantemente. De estos pequeños municipios 1.509 (el 18,5\% del total) no llegan a 250 habitantes, y 1.271 (el $15,6 \%$ del total) ni siquiera a 100.

\subsection{Ayuntamientos de menos de 20.000 habitantes}

Los Ayuntamientos de menos de 20.000 habitantes existentes en España son 7.723, es decir, el 95 $\%$ del total, agrupando al $31,5 \%$ de la población, es decir, casi 1 de cada 3 habitantes vive en este tipo de municipios, y son los que se deben tener en cuenta principalmente a la hora de hacer cualquier tipo de regulación sobre el redimensionamiento de la planta local. Estos municipios, excepto los del País Vasco y Navarra por los motivos expuestos, destinaron a la prestación de servicios públicos locales una media en el período estudiado de 965 euros por habitante. Y para la financiación de estos gastos generaron una media de ingresos de 1.013 euros por habitante, un $5 \%$ más que aquellos a los que hacer frente. 


\subsection{Ayuntamientos de menos de $\mathbf{5 . 0 0 0}$ habitantes}

Los Ayuntamientos de menos de 5.000 habitantes existentes en España son 6.825, es decir, el 84 \% del total, agrupando al $12,5 \%$ de la población, habiendo destinado a la prestación de servicios públicos locales una media de 1.011 euros por habitante, es decir, al bajar a este tramo de población los servicios ya se encarecen un 4,8\% con respecto a la media de los Ayuntamientos de menos de 20.000 habitantes.

En este tramo de población el área de gasto al que se dedicaron mayores recursos fue el de la prestación de servicios públicos básicos con un 40,36 \% del total, seguidas de las actuaciones de carácter general que supusieron un $25,42 \%$, mientras que a las actuaciones de protección social destinaron el $9,40 \%$ del total.

Para la financiación de estos gastos, los Ayuntamientos de menos de 5.000 habitantes generaron una media de ingresos de 1.057 euros por habitante, un $4,5 \%$ más que el total de aquellos a los que tienen que hacer frente, proviniendo los principales de transferencias corrientes que suponen el $45,6 \%$ del total, seguidas ya de lejos por los impuestos, tanto directos como indirectos, que suponen el $23,7 \%$, por las transferencias de capital que representan casi el $16 \%$, y ya muy de lejos de las tasas y precios públicos que bajan hasta el $10,8 \%$.

\subsection{Ayuntamientos de menos de 1.000 habitantes}

Los Ayuntamientos de menos de 1.000 habitantes existentes en España son 4.955, es decir, el 61 \% del total, agrupando al $3 \%$ de la población, habiendo destinado a la prestación de servicios públicos locales una media total de 1.180 euros por habitante, con lo que se confirma que al seguir bajando los tramos de población los servicios suponen un mayor esfuerzo económico para los vecinos de esos municipios, a pesar de que la intensidad de los mismos disminuye, de forma que son un $23,3 \%$ más caros que los realizados por los que tienen una población entre 1.001 y 5.000 habitantes, y un $26 \%$ más de lo que suponen a los que están entre 5.001 y 20.000 y hasta un $26,5 \%$ más que los que se encuentran entre los 5.001 y los 7.000 habitantes.

De los costes anteriores el área de gasto al que los Ayuntamientos de menos de 1.000 habitantes dedicaron mayores recursos fue, también, a la de los servicios públicos básicos, representando el $38,5 \%$ del total, seguido de las actuaciones de carácter general que supusieron el $30 \%$, mientras que a la prestación de servicios sociales fue tan solo el $6,86 \%$.

De lo anterior se concluye que a menor población mayores gastos de organización y funcionamiento, y por tanto improductivos, y menor atención a los propios servicios. Así a la prestación de servicios públicos básicos destinan 2,5 puntos menos que los Ayuntamientos de entre 1.001 y 5.000 habitantes pero hasta 6 puntos menos que los que están entre 5.001 y 20.000 , así como 3,5 puntos menos en servicios sociales que los de 1.001 a 5.000 y 27 menos con respecto a los de 5.001 a 20.000 , y todo ello a cambio de destinar 6 puntos más en gastos generales que los de entre 1.001 a 5.000 y hasta el doble de los que están entre 5.001 y 20.000 habitantes.

Para la financiación de estos gastos, los Ayuntamientos de menos de 1.000 habitantes generan una media de ingresos de 1.234 euros, un 4,6 \% más que el total de los gastos a los que tienen que hacer frente, proviniendo los principales ingresos de las transferencias de otras Administraciones, suponiendo el $53 \%$ del total, de ellas las corrientes suponen el $27 \%$ y las de capital el $26 \%$, seguidas por los impuestos, que suponen el 22,5\%, de ellos los impuestos directos son el $20 \%$ y los indirectos tan sólo llegan al 2,5 \%, y por las tasas y precios públicos que se quedan en un 13,5\%. Lo anterior denota la dependencia que tienen estos «microayuntamientos» del resto de Administraciones a través de las transferencias tanto corrientes como de capital, que suponen más de la mitad de todos sus ingresos.

\subsection{Ayuntamientos de entre 5.000 y 7.000 habitantes}

Se han escrito ríos de tinta sobre cuál debería de ser el tamaño óptimo de los Ayuntamientos, aunque creo que hay que trascender la cuestión teórica para procurar fórmulas que los hagan viables no sólo económicamente, sino y sobre todo, socialmente, pues sin esto no tienen futuro e ir a municipios de 10.000 ó 20.000 habitantes, como se ha indicado por algunos, me parece una absoluta utopía, al menos en estos momentos. También se ha escrito mucho sobre cuál debería ser el tamaño mínimo, y ahí también se han ba- 
rajado distintas opciones considerando que la que más adeptos reúne es la que establece esa dimensión en los 5.000 habitantes, a la que yo me apunto como criterio general, pero siempre como un punto de partida en torno al cual se debería trabajar, con las excepciones que la realidad nos indique, intentando no bajar nunca de los 4.000 e intentando sobrepasarla siempre que sea posible. Es decir, se trataría de terminar con lo que podríamos denominar «minifundismo municipal» y que debe ser el objeto prioritario y urgente de una política de redimensionamiento de la planta local española, que no es otra que las fusiones de Ayuntamientos.

El objetivo que se plantea es conseguir Ayuntamientos con una población de entre 5.000 y 7.000 habitantes, que es lo que, como se desprenderá de este estudio, resulta mucho más sostenible, y ello por diversos motivos, entre otros y no menores, por cuestiones económicas, como consecuencia del aumento de un $17 \%$ que tendrían en la participación en los ingresos del Estado al superar los 5.000 habitantes, en aplicación del artículo 124.1.a) del Texto Refundido de la Ley Reguladora de las Haciendas Locales, aprobado por el Real Decreto Legislativo 2/2004, de 5 de marzo (LRHL), a lo que habría que sumar un $10 \%$ adicional previsto para las fusiones municipales por el artículo 13.4.a) de la LBRL, introducido por la LRSAL.

En España hay 290 Ayuntamientos de entre 5.000 y 7.000 habitantes, representando actualmente el $3,5 \%$ del total, agrupando también al 3,5\% de la población, más, incluso, que los 4.955 Ayuntamientos con menos de 1.000 vecinos. Habiendo destinado a la prestación de servicios públicos locales una media total de 932 euros por habitante, es decir, menos que los de cualquiera de las otras horquillas de población que hemos visto, dato este que corrobora mi afirmación de considerar a los de este tramo como mucho más sostenibles. Así, estos prestaron sus servicios por un 7,8 \% menos que los que tienen menos de 5.000 habitantes, y aún un $0,5 \%$ más barato que los que están entre 7.001 y 20.000 habitantes.

Todo lo anterior refuerza la tesis de que estos Ayuntamientos son mucho más sostenibles que los de población inferior. Así, son capaces de prestar más y mejores servicios a la población destinando, en conjunto, 79 euros menos por habitante que los que tienen menos de 5.000 , lo que demuestra que en estos más pequeños, a pesar de prestarse con mucha menos intensidad, los servicios públicos salen mucho más caros al haber menos población sobre la que repercutir los costes. Si nos fijamos en la prestación de servicios sociales los Ayuntamientos de entre 5.000 y 7.000 habitantes destinan 19 euros más por habitante que los que no llegan a los 5.000, y prácticamente al mismo coste que los de los tramos superiores, sólo 4 euros más per cápita que los que tienen entre 7.001 y 20.000 habitantes. Por lo que respecta a las actuaciones de carácter general, a medida que aumenta la población disminuyen estos gastos corrientes y de funcionamiento: nada menos que 73 euros per cápita menos que los que están por debajo de los 5.000 habitantes.

En el capítulo de inversiones los Ayuntamientos con menos de 5.000 habitantes dedican una media de 317 euros per cápita, representando un $43,4 \%$ más que los 221 euros que dedicaron los que están entre 5.000 y 7.000 habitantes. ¿Quiere esto decir que los municipios más pequeños tienen mayor capacidad inversora?. Ni mucho menos. Lo que sucede es que cualquier obra que hagan, debido a la falta de habitantes, tiene mucha más repercusión per cápita, es decir, necesita de mucho mayor esfuerzo económico por parte de sus vecinos que las realizadas en aquellos otros de más población y donde el reparto general de gastos es sobre una base mayor. Si no ¿cómo se explica que los que están en el siguiente tramo, de entre 7.001 y 20.000 habitantes, aún destinen menos, en concreto 193 euros per cápita, a inversiones?

\section{GRÁFICO 5: COMPORTAMIENTO DE LOS PRINCIPALES PROGRAMAS DE GASTO POR TRAMOS DE POBLACIÓN}

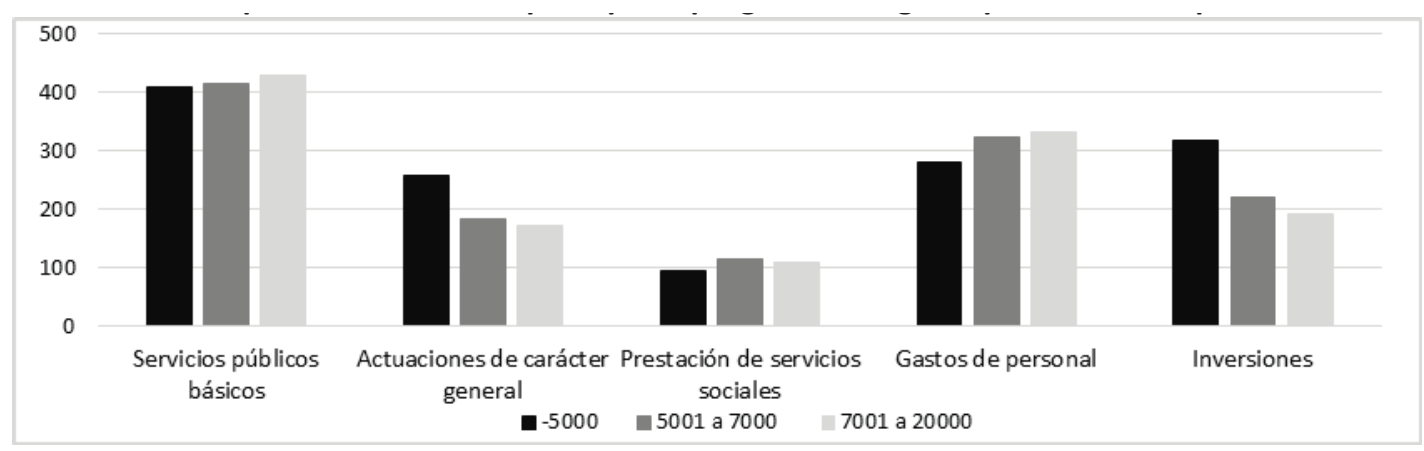

Fuente: elaboración propia

Para la financiación de sus gastos, los Ayuntamientos de entre 5.000 y 7.000 habitantes generan una media de ingresos de 974 euros por habitante y año, un 4,5\% más que el total de los gastos a los que tienen 
que hacer frente, proviniendo principalmente de impuestos, tanto directos como indirectos, que suponen en su conjunto el $31,2 \%$ del total, seguidos por las transferencias corrientes con un $29 \%$, de las tasas y precios públicos que bajan al $17 \%$ y de las transferencias de capital que están en el $12,5 \%$ del total.

GRÁFICO 6: COMPORTAMIENTO DE LOS PRINCIPALES CAPÍTULOS DE INGRESOS POR TRAMOS DE POBLACIÓN

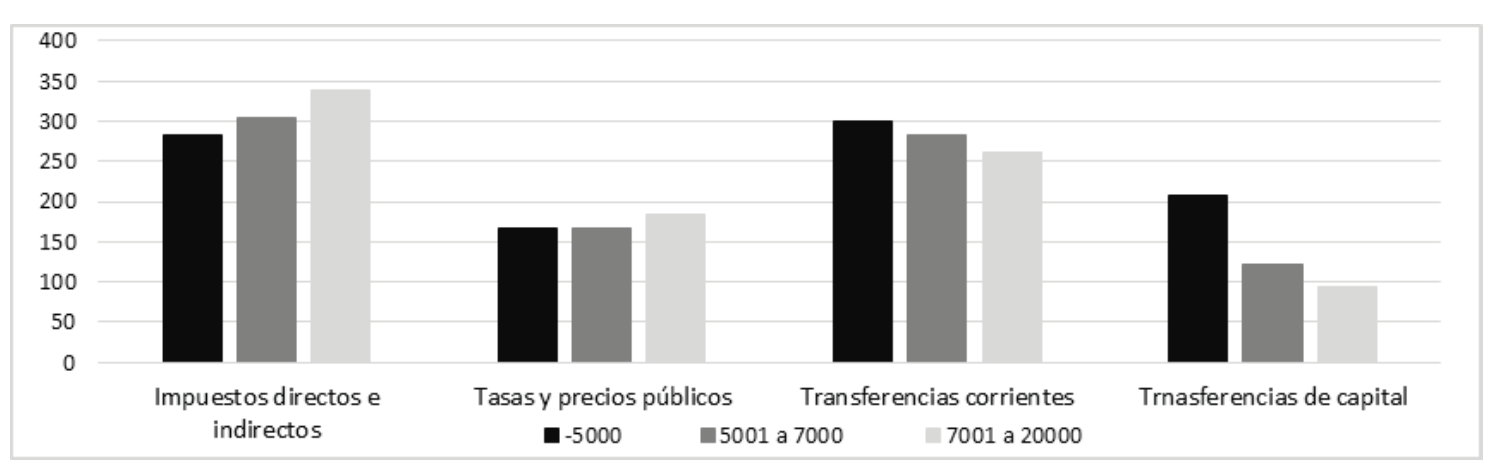

Fuente: elaboración propia

Del estudio comparativo general de ingresos se desprende que cuanto menor es el Ayuntamiento menor es también su capacidad recaudatoria. Así en el capítulo de impuestos los municipios de entre 5.000 y 7.000 habitantes recaudan en términos per cápita un $7,2 \%$ más que los que tienen menos de 5.000 , sobre todo por impuestos directos, donde el diferencial está en el 8,5\%. Sin embargo la recaudación por tasas y precios públicos es muy similar, mientras que la dependencia de los ingresos provenientes del resto de Administraciones públicas a través de las transferencias tanto corrientes como de capital es mayor, y por tanto con menor autonomía municipal por falta de suficiencia financiera, de los municipios según disminuye su población. Y ello a pesar de que en el tramo de entre 5.000 y 7.000 habitantes el conjunto de estas transferencias suponen el $41,6 \%$ del total de sus ingresos, pero es que en los que tienen menos de 5.000 sube hasta el $48 \%$ (6,4 puntos porcentuales más).

\section{LOS GOBIERNOS PROVINCIALES}

La LRSAL otorga un papel determinante a favor de las Diputaciones provinciales o entidades equivalentes, que todo parece indicar que se refiere a los Consejos y Cabildos Insulares e incluso a las Comunidades Autónomas uniprovinciales a pesar de no ser éstas Administración Local, que podría suponer el traspaso de competencias a las mismas de hasta las del $95 \%$ de los Ayuntamientos (los de menos de 20.000 habitantes) por cuestiones estrictamente económicas a través de un más que discutible sistema de coordinación. Pero si examinamos con atención los servicios a que se refiere (recogida de residuos, limpieza viaria, abastecimiento domiciliario de agua potable, acceso a los núcleos de población, pavimentación de las vías y tratamiento de residuos) tendría más sentido que en el momento en que vivimos estos fueran propios de unas Diputaciones, o entidades equivalentes, convenientemente redefinidas porque su asunción con carácter supramunicipal podría suponer un ahorro en los gastos de organización y planificación de los mismos, a lo que podríamos sumar la centralización de determinados suministros, como el de energía eléctrica, telefónico y otros o instaurar una central de compras, y a mayores deberían poner a disposición de los Ayuntamientos los medios técnicos y humanos para optimizar las posibilidades de financiación europea o de otra índole para determinados proyectos o la infraestructura necesaria para la puesta en común entre varios de determinadas iniciativas, de forma que en todos estos casos se generaría un importante ahorro, mucho mayor que el que se puede conseguir a través de las actuales figuras asociativas municipales.

\subsection{Diputaciones Provinciales de Régimen Común}

Lo primero que habría que determinar es si el comportamiento de las Diputaciones ha sido ajustado al papel que legalmente les corresponde. Así, si acoplamos sus competencias a las áreas de gasto que componen la estructura de los presupuestos de las entidades locales comprobamos que la inmensa mayoría de ellas se encuadran dentro de los denominados «servicios públicos básicos». ¿Pero será esta el área de 
gasto principal en la actuación de las Diputaciones?, pues parece que sí, junto a las actuaciones de carácter económico, sobre todo en lo referente a gastos en infraestructuras, situándose en torno al $30 \%$ del total en cada caso, seguidas de las actuaciones de carácter general que suponen el $20 \%$, mientras que a servicios sociales dedican el $16,5 \%$.

Si nos fijamos en los capítulos de gastos, son los de personal los que más peso tienen, suponiendo el $27 \%$ del total, mientras que a inversiones destinan el $16 \%$, lo que acredita uno de los mantras que pesan sobre estas Corporaciones como es el exceso de plantilla, aunque hay bastante diferencia entre unas Diputaciones y otras, así las que porcentualmente soportan mayores costes de personal son la de Cádiz con un $39 \%$ sobre el total de sus gastos, la de Ourense con un 39,7, la de Segovia con un 41,4 y, sobre todo, la de Albacete con un $47,6 \%$, mientras que en las que menos peso tienen sus plantillas son en la de A Coruña con un $20 \%$, la de Castellón con un $19,5 \%$, la de Girona con un $16,8 \%$, la de Huesca con un $14,5 \%$ y la de Valencia con un $13,6 \%$,.

Por lo que se refiere a los ingresos los más importantes son las transferencias corrientes, que suponen el $57,5 \%$ del total, teniendo una especial incidencia las transferencias procedentes de la Administración del Estado, que suponen en torno al $90 \%$ del total, seguidas muy de lejos por las de las Comunidades Autónomas con un $9 \%$.

También es interesante referirse a los datos sobre estabilidad presupuestaria de las Diputaciones provinciales. Así, de los datos comparados se desprende que estas, en su conjunto, son también una Administración equilibrada presupuestariamente, con recursos suficientes para hacer frente a sus gastos, con un diferencial de +3 puntos. No obstante lo anterior, si confrontamos entre si las operaciones corrientes de ingresos con las de gastos nos dará unos resultados distintos. Así, el diferencial total entre ingresos y gastos durante el período estudiado fue, en total, de +33 puntos. Pero si además en los gastos incluimos el Capítulo 9, de pasivos financieros, el diferencial estaría en +17 puntos, con lo que también se constata que las Diputaciones tienen recursos propios no sólo para hacer frente a sus gastos corrientes sino también a su deuda. Por lo que queda claro que, en definitiva, las dificultades de financiación vienen siempre, como en el caso de los Ayuntamientos, por la prestación de servicios ajenos sin que haya una corresponsabilidad ni en la financiación ni en el compromiso de pago por parte de las otras Administraciones intervinientes, fundamentalmente, las Comunidades Autónomas.

Si descendemos al dato por provincias, hubo 9 Diputaciones que no tuvieron grandes diferencias entre los recursos per cápita destinados a servicios públicos básicos y los destinados a gastos generales, en unos casos unas por encima un área de gasto sobre la otra y en otros al contrario, pero siempre en unas ratios muy similares entre ellas, siendo estas las de: Alicante, Cádiz, Castellón, Granada, Guadalajara, Jaén, Lugo, Valencia y Zamora. Por otra parte 7 Diputaciones actuaron más acordes con lo que debería ser su comportamiento y le dedicaron un mayor porcentaje de recursos a los servicios públicos básicos que a los gastos generales, siendo estas las de: Girona, León, Ourense, Palencia, Soria, Toledo y Zaragoza. Todas las demás lo hicieron a la inversa, destinaron un mayor porcentaje de gasto a las actuaciones de carácter general que a los servicios públicos básicos.

\subsection{Las Diputaciones Provinciales y los Ayuntamientos de menos de $\mathbf{2 0 . 0 0 0}$ habitantes}

Una frase manida es la de que «mientras haya Ayuntamientos pequeños habrá Diputaciones», y la cuestión está en determinar cuáles son esos Ayuntamientos pequeños y parece haberse instalado la idea de que son los de menos de 20.000 habitantes, a pesar de ser el $95 \%$ del total de los municipios españoles, por lo que no sólo es que sean los más pequeños sino que además son la inmensa mayoría, porque España no es un país de ciudades sino de pueblos y villas.

Precisamente esa barrera de los 20.000 habitantes ha quedado consagrada con la LRSAL al establecer, en su artículo 26,2, la coordinación por parte de las Diputaciones provinciales de determinados servicios básicos a esos Ayuntamientos. Pues bien, creo que resultará clarificador la comparación de las cuentas presentadas por los Ayuntamientos de menos de 20.000 habitantes con respecto a las de las Diputaciones, aunque no teniendo las cifras de éstas referidas a su actuación con esos municipios se han tomado en consideración la totalidad de sus cuentas, promediadas por el período estudiado.

Si nos fijamos en las áreas de gasto resulta que lo destinado a la prestación de servicios públicos básicos por las Diputaciones es tan sólo el $17 \%$ de lo que hicieron los Ayuntamientos de menos de 20.000 habitantes, y si nos fijamos en su peso específico sobre el total de gastos, en el caso de las Diputaciones supusieron el $28,5 \%$ mientras que en los Ayuntamientos fue del $41 \%$, es decir, hay un diferencial a favor 
de estos últimos de 12,5 puntos, sin embargo sí hay una mayor prestación de servicios sociales por parte de las Diputaciones que por parte de los Ayuntamientos, así en aquellas supusieron el 16,5\% del total de sus gastos mientras que en estos se quedaron en el $11 \%$. Por su parte, al pago de deuda pública las Corporaciones provinciales destinaron casi el $10 \%$ de sus gastos mientras que los Ayuntamientos de menos de 20.000 habitantes destinaron el 5,5\%, es decir, casi la mitad. En los gastos de personal la cuestión se invierte, lógicamente ya que son muchos más los Ayuntamientos que las Diputaciones, siendo el resultado en favor de estas, que dedicaron el $27 \%$ del total, de 5 puntos porcentuales menos con respecto a aquellos, que destinaron el $32 \%$.

\section{GRÁFICO 7: COMPARATIVA DEL PORCENTAJE SOBRE EL TOTAL DE GASTOS DE LAS ÁREAS MÁS SIGNIFICATIVAS}

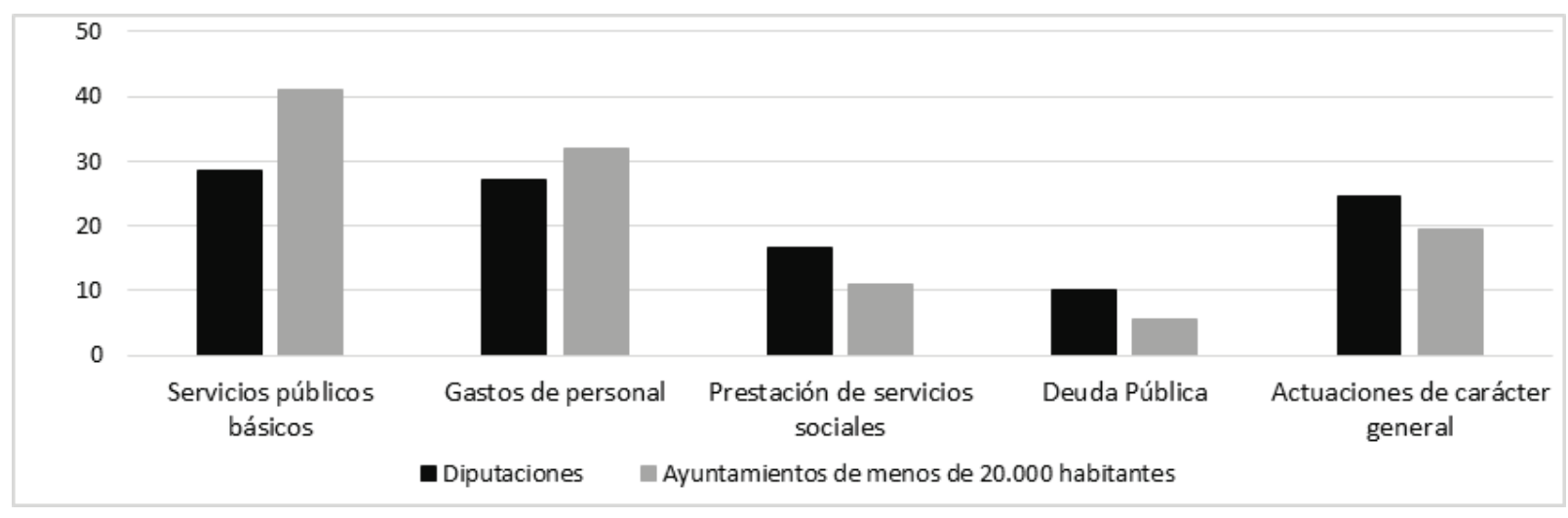

Fuente: elaboración propia

\subsection{Las Comunidades uniprovinciales}

No todo el gasto que queda indicado en este punto referido a las Diputaciones, Consejos y Cabildos Insulares es el total de gasto que podríamos denominar «provincial» ya que faltaría por computar el realizado por las Comunidades Autónomas uniprovinciales, en las que no existen Diputaciones, lo que supone, entre otras cosas, carecer de un órgano de gobierno provincial perteneciente a la Administración Local, porque la Comunidad Autónoma no lo es, ni siquiera se le parece. Su organización y comportamiento recuerda más a la Administración del Estado que a la Local, que tiene sus propias características, absolutamente diferentes de estas otras dos.

De los datos resultantes de las liquidaciones presupuestarias de las Comunidades Autónomas, publicadas en la web del Ministerio de Hacienda y Función Pública durante el período estudiado lo primero que debe acreditarse es si efectivamente las Comunidades uniprovinciales suplen en la práctica a las Diputaciones. Pues bien, si nos fijamos en las transferencias efectuadas a sus entidades locales veremos que, en términos per cápita, las de las uniprovinciales están muy lejos de las realizadas por las pluriprovinciales. De hecho en estas suponen una media de 132 euros por habitante frente a los 59 de las uniprovinciales, es decir, éstas están un $44,7 \%$ por debajo de aquellas, cuando parecería que debería ser al revés al tener que incluir en sus presupuestos las que se supone que deberían ser en lugar de las que en las otras Comunidades realizan las Diputaciones. Si descendemos al detalle de estas transferencias vemos que las que realmente indican el compromiso de las Comunidades con la financiación de sus municipios, que son las corrientes, por tanto no finalistas y destinadas a los gastos de funcionamiento y prestación de servicios propios, estas ascienden en las uniprovinciales a 46 euros por habitante frente a los 89,5 de las pluriprovinciales. Y si ponemos el acento en las de capital, por tanto finalistas y que van más a favor de las inversiones y desarrollo de sus entidades locales, aquí la cosa empeora ya que las Comunidades uniprovinciales destinan 13 euros per cápita frente a los 42,5 de las pluriprovinciales.

Con todo lo anterior tenemos una conclusión clara, como es la gran diferencia en el comportamiento de las Comunidades pluriprovinciales y la organización provincial existente en las mismas con el de las uniprovinciales en relación con sus respectivos Ayuntamientos, que parece dejar claro que la supresión de las Diputaciones en éstas supone en la práctica la anulación del comportamiento que le correspondería a esas Corporaciones provinciales, precisamente por lo que ya se ha indicado y es que las Comunidades Autónomas no son Administración Local, y estos datos lo acreditan absolutamente. 
GRÁFICO 8: COMPARATIVA DE LAS TRANSFERENCIAS ENTRE COMUNIDADES UNIPROVINCIALES Y PLURIPROVINCIALES

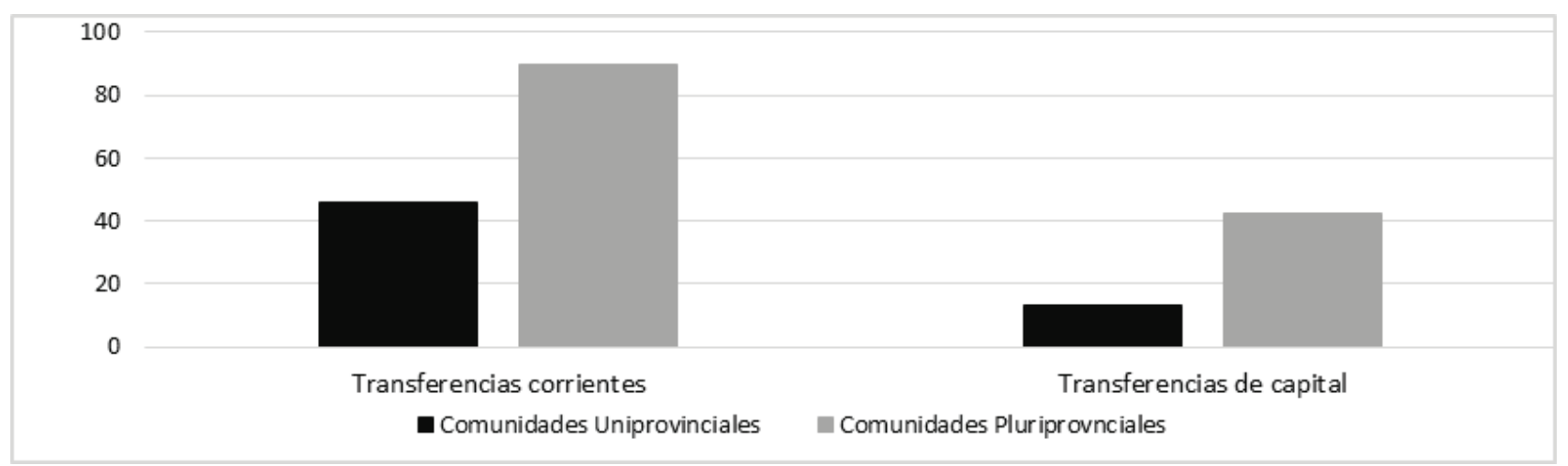

Fuente: elaboración propia

\section{OTRAS FIGURAS ASOCIATIVAS MUNICIPALES}

Está claro que la mayor figura asociativa municipal que existe en nuestra Administración Local es la de las Diputaciones provinciales o entidades equivalentes, a la cual se ha dedicado el punto anterior, pero hay otras figuras que siempre se suelen citar cuando se plantea la necesidad de reformar la planta local, y en contraposición a la figura de la fusión de Ayuntamientos como solución al actual minifundismo municipal, como son las Mancomunidades, las Comarcas y, en menor medida, las Áreas Metropolitanas.

\subsection{Mancomunidades}

La siguiente figura asociativa con mayor presencia en el sector público local, por detrás de las Diputaciones, son las Mancomunidades, aunque a mucha diferencia de aquellas, y que últimamente han estado muy en boga como consecuencia de las cada vez más insistentes propuestas de fusiones municipales a las que se oponen la inmensa mayoría de nuestros políticos locales, amparándose, como alternativa, en las distintas fórmulas de cooperación intermunicipal, y destacando sobre todas a las Mancomunidades. Pero ¿esto es un argumento en serio o simplemente una excusa para evitar tratar sobre las fusiones?

Según el Registro de Entidades Locales del Ministerio de Hacienda y Función Pública existen un total de 998 Mancomunidades, aunque, como en el resto de este trabajo y por los motivos que ya han quedado indicados, si no tenemos en cuenta los datos referidos tanto al País Vasco como a Navarra el número de Mancomunidades registradas es redondo: 900, sin embargo en 2015 sólo habían enviado sus cuentas al Ministerio de Hacienda y Función Pública 534 Mancomunidades, es decir el 59,3 \% del total. Pues bien, con estos datos parece que la respuesta a la anterior pregunta es fácil: no parece muy creíble que la solución a los problemas de los pequeños Ayuntamientos sea la propuesta de acudir a las Mancomunidades cuando hasta ahora no se ha hecho, pues no solamente suponen una parte muy pequeña del gasto del sector público local sino que casi la mitad ni siquiera presentan sus cuentas, seguramente porque muchas de ellas no tienen actividad.

Resulta muy clarificador hacer un pequeño repaso por el tipo de Mancomunidades de las que se tienen datos. Así, el 78 \% están integradas por Ayuntamientos de menos de 5.000 habitantes, aunque también las hay de sólo 100, 200, 300 ó 500 habitantes y compuestas por tan sólo dos o tres municipios, lo cual no parece tener mucho sentido. Por el volumen de población un total de 32 Mancomunidades cuentan con menos de 1.000 habitantes. Pero si estos números los referimos no a la totalidad de Mancomunidades sino a aquellas que pueden tomarse como referencia de los Ayuntamientos a los que les son de aplicación las medidas más cuestionables de la LRSAL, el resultado de las que no sobrepasan los 6.000 habitantes son 6 de cada 10 , y parece razonable que si pueden prestar sus servicios como Mancomunidades también lo podrían hacer como Ayuntamientos, por lo que parece que precisamente la situación actual de estas, su dimensión y comportamiento en cuanto a sus obligaciones formales de rendición de cuentas, aconsejaría su disolución y conversión en Ayuntamientos fusionados. 
Dicho todo lo anterior, voy a entrar en la actuación real de las Mancomunidades según los datos facilitados al Ministerio de Hacienda y Función Pública. Así, tanto de la Disposición transitoria undécima de la LRSAL como del estudio de los Estatutos de la generalidad de las mismas, se desprende que sus fines o servicios repercuten en todas las áreas de gasto que componen la estructura de los presupuestos de las entidades locales, aunque con muy distintos porcentajes. Así, el $54 \%$ del total se destinó a la prestación de servicios públicos básicos, que son el grueso de los que realizan estas entidades, seguidos, ya muy de lejos, de los de protección y promoción social, con un $17 \%$, ocupando los gastos generales una destacada tercera posición, con un $15 \%$, muy cerca de los anteriores.

\subsection{Comarcas}

Según el Registro de Entidades Locales del Ministerio de Hacienda y Función Pública, en España existen 81 Comarcas, 32 de ellas en Aragón, 1 en Castilla y León, 41 en Cataluña y 7 en el País Vasco, que según los datos que facilitaron el mayor volumen de gasto es el referido a la prestación de servicios públicos básicos con un $28 \%$, seguido muy de cerca de la producción de bienes de carácter preferente con un 27,5 $\%$, llegando los gastos generales hasta el $18 \%$.

\section{3. Áreas Metropolitanas}

Según el Registro de Entidades Locales del Ministerio de Hacienda y Función Pública, en España existen tres Áreas Metropolitanas, 1 en Cataluña, la de Barcelona que comprende 36 Ayuntamientos, y 2 en la Comunidad Valenciana, la de tratamiento de residuos que comprende 45 Ayuntamientos, y la de servicios hidráulicos que comprende 51 , entre los que se incluyen todos los de la otra área, ambas en la provincia de Valencia, y que según los datos facilitados el mayor volumen de gasto es el referido a la prestación de servicios públicos básicos, como no podía ser de otra manera según los fines a que se dedican, representado un $66,75 \%$ de su gasto total, seguidos de las actuaciones de carácter económico con un $23 \%$, mientras que los gastos generales supusieron tan sólo un $9 \%$.

Cada una de estas fórmulas pueden seguir teniendo su vigencia, con independencia de que haya una redimensión de la planta local, pero con conceptos y definiciones distintas, suprimiendo aquellas que, sobre todo en el caso de las Mancomunidades, realmente están funcionando ya casi como si fueran Ayuntamientos fusionados, o, incluso también aquellas comarcas que, en realidad, no suponen otra cosa que un órgano intermedio más en el entramado local sin aportar ningún plus sobre la nueva concepción municipal propuesta. Por su parte creo que la figura del área metropolitana puede resultar muy interesante, sobre todo para aquellos municipios que se encuentren en el ámbito de influencia de las ciudades, pero, al igual que sucede con las Diputaciones, con una definición distinta a la actual.

\section{ENTIDADES DE ÁMBITO TERRITORIAL INFERIOR AL MUNICIPIO}

Esta figura, con mayor o menor incidencia, la hay en casi todas las Comunidades Autónomas y de lo que se trata es de determinar la influencia de las mismas en el total del sector público local y si tiene sentido su existencia hoy en día, sobre todo teniendo en cuenta que la LRSAL no apuesta decididamente por su continuidad.

Según el Registro de Entidades Locales del Ministerio de Hacienda y Función Pública, existen un total de 3.714 Entidades de Ámbito Territorial Inferior al Municipio, aunque, como en el resto de este trabajo, si no tenemos en cuenta los datos referidos tanto al País Vasco como a Navarra, el número de las registradas es de 3.036 .

Del estudio de su comportamiento, de los datos presentados podemos ver que el mayor volumen de gasto se refiere a las actuaciones de carácter general, concretamente el $34,88 \%$. En cuanto a los gastos productivos o referidos a sus fines, el mayor porcentaje, un $29 \%$ sobre el total, se lo lleva la prestación de servicios públicos básicos, seguidos de la producción de bienes de carácter preferente con un 16,3\%, y de las actuaciones de carácter económico con un $12 \%$, fundamentalmente por el gasto en infraestructuras. Mientras que otra de las pruebas de que no se trata de verdaderas Administraciones públicas es que a la prestación de servicios tan importantes para la población como son los servicios sociales sólo le dedican el $5,85 \%$ de su gasto total. 
GRÁFICO 9: COMPARATIVAS DE LAS PRINCIPALES ÁREAS DE GASTO DE LAS ENTIDADES LOCALES MENORES

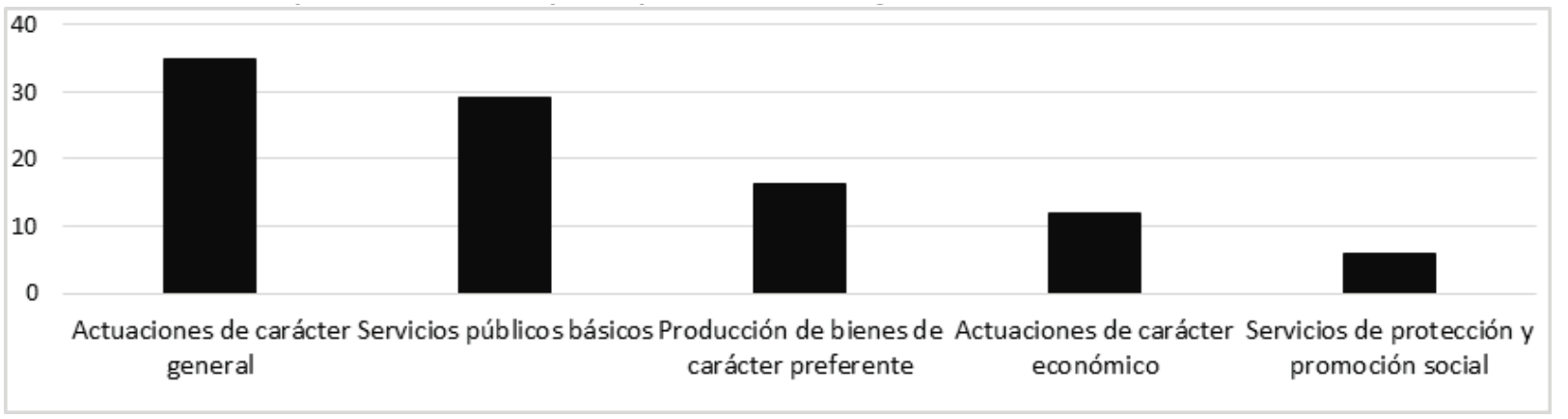

Fuente: elaboración propia

Del comportamiento de estas Entidades manifiesto mi convencimiento de que no deberían existir tal y como las conocemos. ¿Deberían, entonces, desaparecer y ser absorbidas por sus respectivos Ayuntamientos?, pues no necesariamente, pero sí creo que deberían dejar de ser entidades locales, y por lo tanto de derecho público, ya que no son verdaderas Administraciones, y pasar a regirse bajo otras fórmulas asociativas pero de derecho privado que les permita una mayor agilidad en sus procedimientos, seguramente mejor gestión de sus fines y, en cualquier caso, muchos menos gastos generales. En este sentido se puede traer a colación el caso de Galicia donde, aun teniendo la mitad de las entidades de población de toda España, sin embargo sólo cuenta con 7 entidades locales menores, funcionando el resto bajo el paraguas de «comunidades de montes» o "asociaciones de vecinos», etc.

\section{CONCLUSIONES}

I. Los Ayuntamientos representan el nivel jurisdiccional de administración y gobierno más cercano a los ciudadanos. Sus competencias responden al modelo teórico del federalismo fiscal y desempeñan un papel vital para el correcto funcionamiento de algunos de los servicios públicos básicos, como seguridad ciudadana, transporte, recogida y tratamiento de residuos, actividad deportiva, etc. Y, como se ha señalado, a medida que aumentan su tamaño se amplía la lista de servicios que prestan.

De los datos que quedan expuestos en este estudio comprobamos que hay unas constantes que se repiten. Así podemos ver la existencia de dos líneas claramente ascendentes en sentido opuesto a la evolución de la población, como son los costes unitarios en la prestación de la globalidad de los servicios públicos locales que se van incrementando a medida que baja el número de habitantes de cada Ayuntamiento, así como los gastos generales, comprensivos de gasto corriente y de funcionamiento y por lo tanto improductivo, que igualmente se incrementa porcentualmente según desciende el tramo poblacional. Por otra parte, también existe otra línea que, al contrario de las anteriores, es claramente descendente, como es la referida al porcentaje de gasto que repercute en la prestación de servicios públicos básicos de forma que a menor población menores recursos para la prestación de estos servicios y viceversa.

Los pequeños Ayuntamientos repercuten mayor cantidad de dinero per cápita según disminuye su población que, finalmente, va a parar en gran medida a las actuaciones de carácter general cuando no son las que mejoran la calidad de vida de los ciudadanos, disminuyendo lo destinado a la prestación de servicios, siendo estos no sólo de peor calidad según vamos descendiendo en tramos de población sino que incluso llegan a ser prestados en precario. Pero no solamente este área de gasto se ve afectada sino también la destinada a servicios tan sensibles como los servicios sociales, con lo que esto supone de abandono de esa población, sobre todo en este tipo de municipios en los que la mayoría es de edad avanzada y con necesidades que deberían ser satisfechas prioritariamente a través de estos servicios sociales, provocando que haya un traslado hacia otros más grandes, con mayores oportunidades, no tanto de trabajo sino de atenciones, y para las que generalmente es necesario estar empadronado en el Ayuntamiento prestador. Si no retenemos esto y no nos damos cuenta de esta realidad, estaremos condenando a aquellos vecinos que no pueden, o no quieren, trasladar su residencia, a la supervivencia a cambio de seguir manteniendo las actuales estructuras municipales. 
II. El tamaño mínimo de los Ayuntamientos debería estar, a mi juicio, entre los 5.000 y 7.000 habitantes, con las excepciones que la orografía, distancias y otros hándicaps nos exijan aunque no deberían de bajar de los 4.000 habitantes, y procurando superar esos 5.000 para obtener el incremento de un $17 \%$ en la participación en los ingresos del Estado por aplicación del artículo 124.1.a) de la LRHL, al que habría que sumar un $10 \%$ adicional previsto para las fusiones municipales en el artículo 13.4.a) de la LBRL introducido por la LRSAL. De los datos manejados se desprende que los Ayuntamientos que se encuentran en aquella horquilla mejoran todos los datos comparativos con los más pequeños. Así con una aportación per cápita similar a la de otros más grandes y a su vez inferior a la que sufren actualmente los habitantes de los pequeños Ayuntamientos, recibirían a cambio una mayor y mejor prestación no sólo de los servicios públicos básicos sino también de los servicios sociales, consiguiendo a la vez un importante ahorro en gasto improductivo. No olvidando que las repercusiones económicas que traería la fusión para la creación de este tipo de Ayuntamientos se refieren tanto al ahorro y al aumento de la participación en los impuestos del Estado como a la preferencia en la asignación de planes de cooperación local, subvenciones, convenios u otros instrumentos basados en la concurrencia durante, al menos, los cinco primeros años siguientes a la fusión.

La repercusión concreta de este aumento de recursos en la prestación de servicios públicos locales, aumentando unos y ampliando y mejorando la prestación de otros, supondría su homologación con los que prestan los que están en tramos de mayor población, desterrando la actual precariedad en la prestación de la mayoría de los servicios básicos y haciendo justicia social en cuanto a la redistribución de los recursos públicos. También se estarían generando otros ingresos vía tasas y precios públicos por la utilización de los servicios que ahora o no se obtienen ante su inexistencia o son absolutamente insuficientes y deficitarias ante la precariedad en su prestación. Con todo esto conseguiríamos que los nuevos Ayuntamientos tuvieran una mayor capacidad económica y financiera y por lo tanto estuvieran en mejores condiciones para poder acudir incluso, si así lo necesitan, a líneas de crédito y empréstito sin que con ello se ponga en riesgo su estabilidad presupuestaria.

De lo que se trata, por tanto, con la fusión de Ayuntamientos no es de otra cosa que poner al servicio de los ciudadanos unas instituciones que sirvan con eficacia y eficiencia las necesidades y exigencias que tienen en pleno Siglo XXI sin perder su naturaleza e idiosincrasia pero adaptándolas de forma que la mayor parte de los recursos públicos que manejan vayan a su redistribución en forma de prestación de servicios y a la reducción del volumen de gasto que acaba en las actuaciones de carácter general, consiguiendo con esto mejorar y aumentar el nivel de vida de sus vecinos, con mayor equidad y equiparación con el resto de Ayuntamientos, sin la brecha que existe actualmente ya no sólo entre los grandes sino también entre los medianos y los pequeños, y de paso equipararlos a la mayoría de países europeos de nuestro entorno, que ya hicieron este proceso a mediados del Siglo pasado.

III. Una figura importantísima en el mundo local es la de las Diputaciones provinciales, pero no tal y como las conocemos hoy, donde es generalmente percibido, y así queda acreditado en el presente estudio, su sobredimensionamiento en relación con las funciones que tienen encomendadas y con las que efectivamente realizan, lo cual debería ser corregido si realmente se pretende que sean el eje alrededor del cual se han de mover el $95 \%$ de los Ayuntamientos, que son los de menos de 20.000 habitantes. Pero curiosamente la LRSAL, que diseña este nuevo papel, no contempla ninguna medida correctora para que las Diputaciones puedan realizarlo con un mínimo de garantía en la calidad e intensidad de prestación de los servicios públicos. Y sin embargo son unos instrumentos que, convenientemente redefinidas, podrían ser tremendamente útiles.

IV. En definitiva, con la fusión de Ayuntamientos, como consecuencia del aumento y/o mejora de los servicios públicos a recibir, habría un mayor asentamiento de la población en el rural, pues ya no sería necesario irse a vivir a otros núcleos mayores cuando no es por cuestiones laborales, con lo que habría un mayor ahorro familiar, o cuando menos mayor disposición de fondos, con las ventajas evidentes que esto trae consigo, poniendo en valor a los pueblos, ya que por supuesto que no desaparecerían sino que tan sólo se trasladaría la sede de toma de decisiones, es decir, la ubicación concreta de su gobierno municipal, pero a una distancia que les será familiar, y por lo tanto cercana.

\section{PROPUESTAS}

Son cuatro las propuestas que se plantean, referidas todas ellas a grandes áreas con un calado social, económico, institucional y de desarrollo muy importante. 


\section{PROPUESTA 1: La fusión de Ayuntamientos}

Como no podía ser de otra manera la propuesta principal que se formula es la fusión de Ayuntamientos, lo cual no es novedoso. Ya en 1990 el Comité de las Regiones de la Unión Europea advertía en un informe, al referirse a la situación de España, que: «es responsabilidad primaria de las Comunidades Autónomas la política de fomentar fusiones o agrupaciones de municipios, o incluso reordenar coactivamente el mapa municipal; pero hasta ahora se limitaron a estimular tímidamente la constitución de mancomunidades de asociación voluntaria».

En este estudio se propone la fusión de los pequeños Ayuntamientos para convertirlos en unas nuevas organizaciones que se sitúen, como mínimo, entre los 5.000 y los 7.000 habitantes, e incluso superiores donde sea posible, y excepcionalmente también inferiores cuando la orografía u otras circunstancias así lo aconsejen, aunque no deberían bajar de los 4.000 habitantes, mediante la agrupación bajo un mismo municipio de todos aquellos que se encuentren en unas isócronas de tiempo de entre 15 ó 20 minutos con respecto a la capitalidad que se establezca.

Lo primero que habrá que hacer es elaborar un mapa de servicios municipales en el que consten los que presta cada uno de los Ayuntamientos, porque al día de hoy no se sabe a ciencia cierta qué servicios prestan, la prueba es que la LRSAL mantiene el mismo catálogo de servicios mínimos por tramos de población que el hasta ahora vigente, cuando no son comparables los Ayuntamientos de 5.000 habitantes de 1985, año de entrada en vigor la LBRL, con los de ahora. Es decir, esa regulación mantiene, y a la baja, el actual sistema competencial de cuando España no era ni parecida a lo que es hoy o lo que pretende ser en el futuro, olvidando que la LBRL supuso entonces el reto de prestar más servicios de los que se daban mientras que mantener ese pírrico catálogo hoy es desconocer el nivel actual de los servicios municipales, cuando deberían haberse estableciendo nuevos retos de cara al futuro como garantía de mejora de la calidad de vida de la población.

Simultáneamente debería elaborarse un mapa de planta en el que se delimiten los ámbitos territoriales para la prestación de los servicios según el criterio de tiempo expuesto anteriormente. Para esto habría que tomar como base las cabeceras de comarca y, aplicando esa ratio de tiempo, establecer el nuevo término municipal. Una vez hecho esto quedarán núcleos fuera de estas nuevas delimitaciones para los cuales habrá que determinar la capitalidad municipal en función de aquel o aquellos de mayor población o del que ya cuente con mayor número de servicios.

Elaborados ambos mapas debemos superponerlos de forma que comprobaremos cuántos servicios se están duplicando innecesaria e injustificadamente dentro de un mismo ámbito territorial y con ello establecer los mecanismos adecuados de corrección de estas situaciones, de manera que se concentren esfuerzos y se optimicen recursos para poder dotar a todos los que se incluyen en el mismo de un mayor número de servicios o una mejora de los existentes sin aumento de la presión fiscal. Con ello tendremos claros cuáles son los servicios que deben prestarse homogéneamente en todos los ámbitos territoriales de similares características.

Constituidos esos ámbitos territoriales será de cuenta de la Oficina autonómica a que se refiere la $2 .^{a}$ propuesta de este estudio el establecer los tiempos en cada caso, vista la realidad física, social, económica, etc., de cada una de las fusiones a llevar a cabo, y por lo tanto la duración mayor o menor del período transitorio en que deben operar dichos ámbitos, pues la realidad no es homogénea y no admite reglas únicas y generales.

Resulta interesante traer a colación alguna de las recomendaciones del Tribunal de Cuentas incluidas en su Informe 931/2011 y que ha venido reiterado en relación con la organización y configuración del sector público local: "la racionalización y la evolución del sector local hacia un modelo más eficaz y eficiente para el desempeño de las competencias que el ordenamiento jurídico otorga a las entidades locales, pasa por el estudio y diseño de un mapa local acorde a las necesidades demográficas, económicas y sociales actuales y orientado a formas más lógicas de prestación de servicios a los ciudadanos, eliminando y evitando, en lo posible, tanto la duplicidad de actuaciones y solapamiento de competencias no sólo entre distintas entidades locales sino entre distintas administraciones públicas en especial, así como la persistente presencia de entidades que no prestan ningún servicio o que carecen de actividad y promoviendo, en su caso, fórmulas de agrupación de entidades para una mayor economía, eficacia y eficiencia en la prestación de servicios».

Es difícil a priori dar una cifra de cuál debería ser el número ideal de municipios en España, y esta habrá de determinarse por cada Comunidad Autónoma a través de la Oficina a que se refiere la siguiente propuesta según un riguroso estudio sobre el terreno, pero en una primera aproximación teórica, una vez estudiada la 
división comarcal de cada provincia española, con excepción de Baleares y Canarias por razones de insularidad y del País Vasco y Navarra por las repetidamente expuestas, la agrupación de los municipios con menos de 5.000 habitantes para crear otros nuevos en torno a ese nivel poblacional, así como relacionándolos con sus respectivas cabeceras de comarca y núcleos afines cercanos, nos daría la transformación de la actual planta local de los actuales 7.445 Ayuntamientos existentes en España, sin contar las Comunidades citadas, a unos 2.500 , es decir, en torno a 5.000 municipios menos, pasando de una media, sin tener en cuenta a los de más de 50.000 habitantes para evitar distorsiones, de los 2.616 vecinos actuales por Ayuntamiento a tres veces más, 8.670 habitantes, siendo esta una cifra homologable a la de nuestros socios europeos.

\section{PROPUESTA 2: Creación de una oficina autonómica de fusiones}

Es primordial la creación de una oficina técnica, y recalco éste adjetivo, que se encargue del estudio, programación, promoción y propuesta de las fusiones que realmente se necesitan. Esta oficina tendría la responsabilidad de llevar a cabo las tareas señaladas en la $1 .{ }^{a}$ propuesta de éste estudio con el objetivo de evitar que se planteen solamente por cuestiones de empatía y con un goteo que no supone ninguna solución general. Esta oficina coordinaría con los Ayuntamientos afectados el período transitorio en que debe operar cada uno de los ámbitos territoriales allí referidos hasta la completa culminación del proceso y, consecuentemente, la aprobación de la creación del nuevo Ayuntamiento resultante de la fusión. Igualmente, sería la encargada de conseguir la financiación para los gastos que se van a ocasionar: unificación de planeamientos urbanísticos, coordinación en la gestión de los servicios, obras en edificios para albergar los nuevos servicios y oficinas centrales, etc. Aunque esto suponga que unos lleven más que otros, porque la igualdad no consiste en tratar a todos de la misma manera sino de forma diferente a las situaciones distintas, para que al final se encuentren en la misma posición, es decir, en iniciar la andadura de esos Ayuntamientos fusionados como si realmente fuesen nuevos, sin hipotecas ni gravámenes, y por lo tanto pudiendo prestar desde el principio los servicios que sus vecinos reclaman y que actualmente no pueden ver satisfechos por la pequeña dimensión de su municipio.

\section{PROPUESTA 3: Modificación de las Diputaciones Provinciales}

Una cuestión que se ha planteado como objeción a las propuestas de fusiones de Ayuntamientos son las reservas de algunos sobre la posibilidad de que éstas supongan una minoración en la representatividad de los miembros de las Corporaciones Locales y, por lo tanto, una pérdida en la calidad democrática de los nuevos Ayuntamientos, argumentación que se cae por su propio peso. Por una parte está demostrado que la cercanía excesiva de los representantes municipales no es directamente proporcional a una mayor eficiencia y calidad democrática, sino que puede llegar a ser todo lo contrario. La presión a la que se encuentran sometidas las autoridades locales por esa cercanía hace que no siempre adopten correctamente las decisiones que debieran. Por otra parte este argumento supondría que la propia aplicación del artículo 179 de la LOREG, que establece la distribución del número de concejales según el número de habitantes, haría que a mayor población menor calidad democrática al ser menos representativos los miembros de los Ayuntamientos según va aumentado su población. Según los últimos datos del Instituto Nacional de Estadística en España hay 1.271 Ayuntamientos con menos de 100 habitantes que agrupan a 73.443 habitantes y para gobernarlos ejercen 3.813 concejales, suponiendo que de cada 19 habitantes de estos «microayuntamientos» 1 es concejal. Y podemos seguir dando datos de una planta municipal absolutamente anacrónica, ya que 1 de cada 3 municipios españoles tiene menos de 250 habitantes en los que se encuentra el $17 \%$ de todos los concejales, 1 por cada 28 habitantes. Con la propuesta que se formula habría una reducción aproximada del $58 \%$ del total de concejales, siendo la mayor en el número de Alcaldías, unas 5.000.

Este tema enlaza con la propuesta de modificación de las Diputaciones provinciales, siendo necesario adaptar su composición política, pues no parece lógico que sigan teniendo una representación de segundo grado o indirecta, a través de representantes que no han sido elegidos directamente por los ciudadanos sino por concejales electos y entre ellos. Sin embargo, con la reducción de Ayuntamientos tras un proceso ordenado de fusiones, el Pleno Provincial debería estar formado por todos los Alcaldes, convirtiéndose así en una verdadera entidad de representación, y por lo tanto también de Gobierno Provincial, pudiendo, incluso, participar con mayor legitimidad en otros foros tanto para las relaciones con la Comunidad Autónoma respectiva, como en reuniones sectoriales o con el Estado. 
Además de la representación, con la conveniente redefinición, las Diputaciones provinciales se convertirían en organismos extraordinariamente útiles para la prestación de determinados servicios como es el caso, por ejemplo, de la recogida de basuras y tratamiento de residuos, el ciclo completo del agua, la prestación del servicio de oficina de supervisión de proyectos o, incluso, la centralización en determinados suministros, como el de energía eléctrica, telefónico y otros o instaurar una central de compras, de forma que en todos ellos se generaría un importante ahorro, mucho mayor que el que se puede conseguir a través de las actuales figuras asociativas intermunicipales. Además, las Diputaciones pondrían a disposición de los Ayuntamientos los medios técnicos y humanos para optimizar las posibilidades de financiación europea o de otra índole, para determinados proyectos o la infraestructura necesaria para la puesta en común entre varios de determinadas iniciativas.

\section{PROPUESTA 4: Reforma de la financiación local}

Con independencia de cuándo se abra el debate sobre el redimensionamiento de la planta local lo que es urgente e inaplazable es iniciar el de la financiación municipal. Esto no solo debe suponer una nueva Ley que la regule, una vez superada la de las Haciendas Locales que nunca fue una auténtica legislación sobre financiación local, sino también de modificación de los actuales comportamientos interadministrativos en ésta materia. No se puede seguir manteniendo la dependencia económica de los Ayuntamientos de un sistema pernicioso de subvenciones que los coloca en un plano de sometimiento con respecto a sus Comunidades Autónomas, se les da un trato impropio de una Administración pública, que es lo que son, recibiendo prácticamente el mismo que si fuesen meras «agrupaciones de vecinos», y además casi se les obliga a participar en la financiación y prestación de servicios netamente autonómicos, cuando estas actuaciones deberían estar presididas por el principio de colaboración y, por lo tanto, de corresponsabilidad en la asunción de los costes. Y desde luego, evitando el anticipo de fondos por parte de los Ayuntamientos, con lo que esto supone de merma en su tesorería, teniendo que acudir en muchas ocasiones a operaciones de endeudamiento, provocando a menudo la desatención de obligaciones propias del municipio. La fusión, y por lo tanto el aumento de entidad de los Ayuntamientos, les pondrá en una posición más ventajosa para poder negociar el cambio de status de esas colaboraciones.

Una de las preocupaciones más importantes de la LRSAL era la financiación de los servicios municipales distintos de los propios. De los datos que reflejan las correspondientes liquidaciones se desprende que, quienes deberían velar por la financiación de los Ayuntamientos, como son las Comunidades Autónomas, marcan una tendencia muy negativa, poniendo en primer lugar sus propias necesidades, aunque ello lleve a desatender las de los municipios de su territorio. De lo que debería tomarse buena nota a la hora de establecer el sistema de financiación local que se considere, teniendo en cuenta que debe favorecerse la autonomía municipal mediante el carácter no finalista de la mayor parte de las transferencias, establecer claramente los criterios y momento de las aportaciones de cada Administración territorial en las actuaciones conjuntas y blindar los ingresos de los Ayuntamientos frente a los vaivenes autonómicos.

\section{REFLEXIÓN FINAL}

España no es un país de ciudades sino de villas y pueblos, ya que el $95 \%$ de los Municipios no llegan a 20.000 habitantes, el $60 \%$ tienen menos de 1.000 , el $47 \%$ menos de 500 y el $14 \%$ ni siquiera llegan a 100 , y prácticamente en todos ellos los servicios que no preste el Ayuntamiento no lo hace ninguna otra Administración. Aquí no hay duplicidades pero sí servicios en precario o falta de ellos, porque el problema de nuestra Administración Local es su mapa de planta.

Nuestra legislación ha vivido de espaldas a la figura de la fusión y lo sigue haciendo a pesar de la LR$\mathrm{SAL}$, ya que, aunque ésta introduce incentivos sin embargo el proceso sigue siendo voluntario, lo que decaerá previsiblemente en ineficaz, por una parte por su dilación en el tiempo y por otra porque las posibles uniones que haya lo serán por afinidad o empatía y no por principios de ordenación y racionalización, sobre los cuales tampoco introduce ningún elemento de fomento sino que estos son tan sólo de carácter económico.

Por otro lado están las fusiones obligatorias, y dentro de estas, las ordenadas y con un proceso transitorio para que no resulten traumáticas mediante el establecimiento previo de unos ámbitos territoriales para la prestación de servicios, que son las que se proponen en este estudio, porque considero que es la forma más «racional» de abordar el asunto para poder contar, realmente, con una Administración Local «sostenible». 
Finalmente creo que es importante traer a colación aquí algunas de las declaraciones aprobadas en el XXXIV Congreso Mundial de la Unión Internacional de Autoridades Locales, celebrado en Barcelona el 24 de marzo de 1999, que reivindicó que los Estados deben ir aceptando la mayor importancia de los gobiernos locales y regionales como agentes democráticos y económicos imprescindibles, en conjunto con otros sectores, y como hilo conductor del desarrollo sostenible de la economía y de la creación y revitalización de puestos de trabajo. Es obvio que los Estados no pueden dirigir y controlar de forma centralizada las ciudades y los pueblos del hoy y del mañana, tan complejos, integrados y en constante evolución. Sólo podrá hacerlo un gobierno descentralizado, que involucre al ciudadano y esté próximo al mismo. Y yo añado: y para que esto pueda llevarse a la práctica es necesario contar con unos Ayuntamientos con la dimensión y estructura suficiente como para poder abordar los retos, no sólo que se les puedan plantear, sino que tienen ya planteados hoy en día encima de la mesa.

\section{BIBLIOGRAFÍA}

DE DIEGO GÓMEZ, Alejandro. (2012). "Hacia la fusión no traumática de Ayuntamientos". http://fusiondeayuntamientos. blogspot.com.es/.

DE DIEGO GÓMEZ, Alejandro. (2014). "La fusión de Ayuntamientos en la Ley 27/2013, de Racionalización y Sostenibilidad de la Administración Local", Revista El Consultor de los Ayuntamientos y de los Juzgados. núm. 5, marzo de 2014.

DE DIEGO GÓMEZ, Alejandro. (2014). "La fusión de Ayuntamientos, con especial referencia a Galicia", Revista Galega de Administración Pública, núm. 47, enero-junio de 2014.

DE DIEGO GÓMEZ, Alejandro. (2015). "Las fusiones de Ayuntamientos", capítulo 8 del libro colectivo La Reforma del Régimen Jurídico de la Administración Local. El nuevo marco regulatorio a la luz de la Ley de Racionalización y Sostenibilidad de la Administración Local. Coordinado por CARRILLO DONAIRE, Juan Antonio y NAVARRO RODRÍGUEZ, Pilar. Wolters Kluwer, marzo de 2015.

DE DIEGO GÓMEZ, Alejandro. (2015). "La planta municipal española. Los ámbitos territoriales para la prestación de servicios como paso previo a la fusión no traumática de Ayuntamientos", Revista La Administración Práctica, núm. 3, marzo de 2015.

DE DIEGO GÓMEZ, Alejandro y VAQUERO GARCíA, Alberto. (2016). "Redimensionamiento de la planta local. Retos frente al minifundismo de Galicia". Red Localis, Documento 5/2016, http://redlocalis.com/wp-content/ uploads/2016/11/Documento_5_2016_redimensionamiento.pdf.

INSTITUTO NACIONAL DE ESTADIISTICĀ. Censo de Población. http://www.ine.es/nomen2/index.do.

MINISTERIO DE HACIENDA Y FUNCIÓN PÚBLICA. Oficina Virtual de las Entidades Locales. http:// serviciostelematicosext.minhap.gob.es/SGCAL/entidadeslocales/.

MINISTERIO DE HACIENDA Y FUNCIÓN PÚBLICA. Oficina Virtual de las Comunidades Autónomas. http:// serviciostelematicosext.minhap.gob.es/SGCAL/publicacionliquidacion/aspx/menulnicio.aspx.

MINISTERIO DE HACIENDA Y FUNCIÓN PÚBLICA. Registro de Entidades Locales. http://ssweb.seap.minhap.es/ $\mathrm{REL} /$ frontend/inicio/index.

CONSEJO DE ESTADO. Dictamen 567/2013, de 24 de mayo, Madrid.

CONSEJO DE ESTADO. Dictamen 338/2014, de 22 de mayo, Madrid.

TRIBUNAL DE CUENTAS. Informe de fiscalización 931/2011, Madrid. 